\title{
Atmosfer ile İlgili Çevre Problemleri Konularında Kavram Yanılgılarını Tespit Eden Üç Aşamalı Tanı Testinin Türkçeye Uyarlanması
}

\section{Ceyhan ÇİĞDEMOĞLU* ～Harika Özge ARSLAN**}

Öz: Bu çalışmanın amacı atmosferde görülen küresel çevre problemlerinden sera etkisi, küresel 1sınma, ozon tabakasının incelmesi ve asit yağmurları hakkındaki kavram yanılgılarını belirlemek için İngilizce olarak geliştirilmiş olan üç aşamalı bir tanı testinin Türkçeye uyarlamasını yapmaktır. Arslan, Cigdemoglu ve Moseley (2012) tarafindan geliştirilmiş geçerliliği ve güvenirliliği raporlanmış test, araştırmacılar tarafından Türkçeye çevrilmiş, daha sonra test uyarlama süreçlerinin aşamaları kullanılmıştır. Ankara'daki bir üniversitede öğrenim gören 207 öğretmen adayına uygulanarak geçerlilik ve güvenirlik çalışması yapılmıştır. Atmosfer ile İlişkili Çevre Problemleri Tanı Testi (AÇPTT)'nin geçerliği hem nitel yöntemler hem de nicel yöntemlerle sağlanmıştır. Katılımcıların toplam puanları ile cevaplarından emin olma düzeyleri arasında pozitif ilişki olması, az kavram yanılgısına sahip olduğu belirlenenlerin, fazla kavram yanılgısına sahip olduğu belirlenenlere göre cevaplarından daha emin olduklarını göstermektedir. Aynı zamanda testin geçerliliğini destekleyen yanlış sebepli doğruların ve doğru sebepli yanlışların yüzdeleri olması gereken aralıkta çıkmıştır, bu değerler sırası ile \%4.77 ve \%3.08'dir. Testin Cronbach alpha güvenirlik katsayısı 0.73 , ortalama zorluk derecesi 0.22 'dir. Testin Türkçeleştirilmesi ulusal

\footnotetext{
* Yrd. Doç. Dr. Ceyhan Çiğdemoğlu, Atılım Üniversitesi, Eğitim Bilimleri Bölümü, Ankara. ceyhan.cigdemoglu@atilim.edu.tr

** Yrd. Doç. Dr. Harika Özge Arslan, Düzce Üniversitesi, Eğitim Fakültesi, Matematik ve Fen Bilimleri Eğitimi Bölümü, Düzce. harikaarslan@duzce.edu.tr
}

$\begin{array}{lll}\text { Gönderim:23.01.2017 } & \text { Kabul:28.02.2017 } & \text { Yayın:15.06.2017 }\end{array}$


eğitim araştırmacılarının ve öğretmenlerin onu tanı, başarı, ya da erişi testi olarak kullanılabilmesi açısından önemlidir.

Anahtar kavramlar: Kavram yanılgısı, küresel 1sınma, sera etkisi, ozon tabakasının incelmesi, asit yağmurları, üç aşamalı test

\title{
Adaptation of a Three-Tier Diagnostic Test Identified Misconceptions on the Atmosphere Related Environmental Problems to Turkish.
}

\begin{abstract}
The purpose of this study is to adapt a three-tier diagnostic test from English to Turkish to assess misconceptions of learners from high school or higher levels, about atmosphere related environmental problems which are about greenhouse effect, global warming, ozon layer depletion, and acid rains. The test as a valid and reliable instrument is developed in English by Arslan, Cigdemoglu and Moseley (2012), then translated into Turkish by researchers, after that, test adaptation producers were employed. Reliability and validity of the test was provided by administrating it to 207 pre-service teachers from a university in Ankara. The reliability of atmosphere related environmental problems diagnostic test (AÇPTT) was proofed by both quantitative and qualitative methods. The positive correlation between participants' total score and their confidence levels indicates that the ones who hold fever misconceptions feel more confident than the ones who have more misconceptions. Besides, the percentages of false positives and false negatives which support the validity are calculated in the expected range, the values are $4.77 \%$ and $3.08 \%$ respectively. The Cronbach alpha reliability coefficient is 0.73 and the mean difficulty index is 0.22 . The translation of the test to Turkish language is important since it provides national education researchers and teachers to use it as diagnostic, formative or summative assessment tool.
\end{abstract}


Key Words: Misconceptions, global warming, greenhouse effect, ozone layer depletion, acid rain, three-tier diagnostic test.

\section{Giriş}

Günümüzde iklim değişikliği yazılı ve görsel medya araçları vasıtasıyla neredeyse her gün karşılaştığımız ve insanoğlunun yüz yüze geldiği en önemli çevre problemi olarak nitelendirilen bir kavramdır. İklim değişikliğgi, "karşılaştırılabilir zaman dilimlerinde gözlenen doğal iklim değişikliğine ek olarak, doğrudan veya dolaylı olarak küresel atmosferin bileşimini bozan insan faaliyetleri sonucunda iklimde oluşan bir değişiklik" (Enerji ve Tabii Kaynaklar Bakanlığı, 2012) olarak tanımlanmaktadır. Küresel ilkim değișikliğinin ana kaynağı insan eliyle gerçekleşen atmosferik değişiklikler olduğuna göre, iklim değişikliği ile mücadele edebilmek için alınan önlemler arasında konu ile ilgili verilecek eğitiminin yeri yadsınamaz (Gowda, Fox ve Magelky, 1997; Kışoğlu, Gürbüz, Erkol, Akar ve Akıllı, 2010). Çünkü toplumsal çevrenin en önemli unsuru olan insanın eğitimi, konu hakkında farkındalık yaratmakta çok önemli bir rol oynar (Taber ve Taylor, 2009). Yaş limiti gözetmeksizin, okul öncesi dönemden yükseköğretime kadar tüm eğitim kademelerinde iklim değişikliklerinin konu edildiği çevre eğitimine ihtiyaç vardır (Darçın, Bozkurt, Hamalosmanoğlu ve Köse 2006). Çevre eğitimi çevre ile ilgili bilgi ve değerlerin öğretildiği ve böylelikle nihai olarak bireylerin gelecek nesilleri de düşünerek çevreye duyarlı davranmalarını amaçlayan kademeli bir süreçtir (Hungerford, Peyton ve Wilke, 1980). Bu nedenle, 90'lı yılların sonundan itibaren çevre eğitimi konuları pek çok Avrupa ülkesinin eğitim programlarına girmiştir (Stokes, Edge ve West, 2001). Ülkemizde ise 2005 yllından itibaren fen ve teknoloji programının yenilenmesi ile 4.- 8. sınıflarda küresel iklim değişikliğini de içeren çevre konuları disiplinler 
arası bir yaklaşım ile işlenmeye başlanmış ve daha sonra 2013 yılında yapılan değişikliklerle birlikte program sürdürülebilir kalkınma bilincine sahip fen okuryazarı bireyler yetiştirmeyi hedeflemiştir. Öğrencilerin günlük yaşantılarından ya da önceki okul kademelerinden beraberlerinde getirdikleri önbilgileri ve kavram yanılgıları diğer tüm konularda olduğu gibi küresel iklim değişikliği konusunda da bulunmaktadır (Karpudewan, Roth ve Chandrakesan, 2015; Shepardson, Niyogi, Choi ve Charusombat, 2009; Shepardson, Niyogi, Roychoudhury ve Hirsch, 2012). Bu çalışmada küresel atmosferin bileşiminin bozulması ile ortaya çıkan çevre problemlerinden adlarını sıklıkla duyduğumuz ve küresel boyutlu olan sera etkisi, küresel ısınma, ozon tabakasının incelmesi ve asit yağmurları konularındaki bilgi ve kavram yanılgıları ele alınmıştır. Çünkü bu önbilgi ve kavram yanılgıları zaman zaman öğrencilerin bu kavramları bilimsel olarak doğru olandan farklı algılamalarına böylelikle farklı tutum ve davranış geliştirmelerine neden olmaktadır. Nitekim alan yazında öğrencilerin sera etkisi (Bozkurt ve Cansüngü Koray, 2002) küresel 1sınma (Darçın ve diğ., 2006; Dawson ve Carson, 2013), ozon tabakasının incelmesi (Bozkurt ve Aydoğdu, 2004; Gungordu, Yalcın-Celik, ve Kılıc, 2017; Pekel, Kaya ve Demir, 2007) ve asit yağmurları (Kara, 2015) ile ilgili pek çok kavram yanılgılarına sahip oldukları belirtilmiştir.

$\mathrm{Bu}$ bilgiler ile ilgili olarak eğitim araştırmacıları önkavramlar (Novak, 1990), alternatif kavramlar (Driver ve Easley, 1978), kavram yanılgıları (Helm, 1980), çocukların bilimsel içgüdüleri (Sutton, 1980) ve kendiliğinden oluşan bilgiler (West ve Pines, 1985) gibi farklı terimler kullanmalarına rağmen aynı tanımlamada hemfikirdirler. Buna göre, öğrencilerin sınıfa gelmeden önce edindikleri bilgilerin pek çoğu bilimsel olarak doğru kabul edilenden farklidır (Clement, Brown ve Zietsman, 1989; Driver, 1988; Hammer, 1996; Treagust, 1988). 70'li y1llardan beri süregelen ve önemini kaybetmeyen kavram ve kavram 
yanılgısı çalışmaları neticesinde günümüzde eğitimciler öğrencilerin beraberlerinde kayda değer miktarda kavram yanılgısı ile sınıfa geldiklerini biliyorlar (Duit ve Treagust, 2012; Vosniadou, 2008). Bu nedenle öğretmenlerin öğretme sürecine başlamadan önce öğrencilerin hali hazırda var olan önbilgilerini dikkate alması gerekmektedir (Amin, Smith, ve Wiser, 2015; Driver ve Easley, 1978). Yapılandırıcı öğrenme yaklaşımı, bu önbilgileri çok önemsemektedir çünkü öğretmenlerin uygun öğretim etkinlikleri kullanması suretiyle bunlar yeniden yapılandırılarak kavram yanılgılarının ortadan kaldırılması sürecinde rol alırlar (Posner, Hewson, ve Gertzog, 1982). Bu bağlamdan bakıldığında öğrencilerin iklim değişikliği ile ilgili bilimsel bilgilere sahip olabilmeleri için öncelikle önbilgilerinin tespit edilmesinin önemi büyüktür. Ancak bu tespiti yapması beklenen öğretmenlerin hali hazırda iklim değişikliği ile ilgili kavram yanılgılarına sahip olmaları öğretmenlerin bu yanılgılarını öğrencilerine aktarmaları sonucunu doğurmaktadır (Dove, 1996; Groves ve Pugh, 1999). Atmosferik iklim değişikliği ile ilgili olarak sıklıkla kullanılan sera etkisi, küresel ısınma, ozon tabakasının incelmesi ve asit yağmurları kavramları alan yazında birçok çalışmaya konu olmuş ve bu konularla ilgili geleceğin öğretmenleri olan öğretmen adaylarının kavram yanılgıları rapor edilmiştir (Arsal, 2010; Boyes, Chambers ve Stanisstreet, 1995; Çimer, Çimer ve Ursavaş, 2011; Daskolia, Flogaitis ve Papageorgiou, 2006; Dove, 1996; Groves ve Pugh, 1999, 2002; Gungordu, Yalcın-Celik, ve K1lıc, 2017; Khalid, 2001; 2003; Oskay, Temel, Özgür ve Erdem, 2012; Pabuçcu; 2016; Summers, Kruger, Childs ve Mant, 2000).

Fen eğitimi alan yazınında amacı belirli konulardaki kavram yanılgılarını tespit etmek olan tanı testleri sıklıkla kullanılmaktadır. Treagust (1988) tarafından geliştirilen iki aşamalı tanı testlerine, cevaptan emin olma endeksi eklenerek bu testlerin olası dezavantajlarının ortadan kaldırılabilineceği önerilmektedir (Eryılmaz, 2010; Hasan, Bagayoko ve Kelley, 1999; 
Pesman ve Eryilmaz, 2010). Bu dezavantajlardan birisi, özellikle katılımcıların tahmine dayalı cevap vermesi nedeniyle kavram yanılgısına sahip olma durumu ile bilgi eksikliği durumunun birbirinden ayırt edilememesidir (Caleon ve Subramaniam, 2010; Pesman ve Eryilmaz, 2010; Arslan ve diğg, 2012). Günümüzde eğitim araştırmalarında sınırlı sayıda çalışma iki aşamalı testlere emin olma endeksi ekleyerek üç aşamalı test geliştirmiş ve uygulamıştır (Arslan, ve diğ, 2012; Saat ve diğg, 2016; Kirbulut ve Geban, 2014; Pesman ve Eryilmaz, 2010; Taslidere, 2016). Bu çalışmalar, üç aşamalı testlerin kavram yanılgıları ile bilgi eksiklikleri arasındaki ayırımı yapabilmekte olduğunu ortaya çıkarmıştır. Örneğin, "küresel ısınma ozon tabakasındaki incelmeden kaynaklanır” şeklindeki kavram yanılgısını likert tipi ve benzeri kapalı uçlu ölçme araçları kullanarak tespit eden çalışmalarda katılımcıların bu yanılgıya en az \%43 ve üzerinde sahip oldukları raporlanmıştır (Boyes ve diğ., 1995; Khalid, 2001, 2003; Michail, Stamou ve Stamou, 2007). Aynı kavram yanılgısı üç aşamalı bir test kullanıldığında ise ilk aşama değerlendirildiğinde \%56, iki aşamada değerlendirildiğinde $\% 40$ ve üç aşamada birlikte değerlendiğinde \%16 olarak bulunmuştur (Arslan ve diğ, 2012). Aradaki bu fark katılımcıların verdikleri cevapların nedenlerini doğru olarak seçememeleri ve cevaplarından emin olmamalarından kaynaklanmaktadır. Bu nedenle bu kişilerin aslında konu le ilgili bilgi eksikleri olduğu ortaya çıkarılmıştır.

Alan yazında atmosfer ile ilgili çevre problemleri konularındaki kavram yanılgılarını belirlemek üzere Türkçe olarak geliştirilmiş tanı testi bulunmaması nedeniyle ülkemizde bu konular ile ilgili kavram yanılgılarını tespit etmek için yapılan çalışmalarda çoğunlukla likert tipi ölçekler tercih edilmiştir (Ayvacı ve Çoruhlu, 2009; Darçın ve diğ., 2006; Kışoğlu ve diğ., 2010). Bu çalışmanın amacı bu eksikliği gidermek amacıyla daha önce araştırmacılar tarafından yurtdışında (Amerika Birleşik Devletleri) İngilizce olarak geliştirilmiş geçerlik ve 
güvenilirlik çalışması yapılmış olan sera etkisi, küresel ısınma, ozon tabakasının incelmesi ve asit yağmurları konularını içeren üç aşamalı tanı testinin Türkçeye uyarlamasını yapmaktır.

\section{Yöntem}

Uyarlama Çalışması: $\mathrm{Bu}$ çalışma bir uyarlama çalışması olduğu için öncelikle çalışmaya dâhil olmayan yazardan izin alınmıştır. Daha sonra Atmosfer ile İlişkili Çevre Problemleri Tanı Testinin (AÇPTT) İngilizce olan orijinal versiyonundaki tüm maddeler araştırmacılar tarafından bağımsız olarak Türkçeye çevrilmiştir. Testin içeriği ile ilgili farkındalığı yüksek iki kimya bölümü öğretim üyesi ve çevre konularında çalışmaları olan iki fen eğitimcisi tarafından da test Türkçeye çevrilmiştir. Tüm bu Türkçe versiyonlar geri çeviri süreci için iki ayrı İngilizce çeviri uzmanı tarafından İngilizceye çevrilmiştir. Geri çevirileri orijinal versiyonla kıyaslanmıştır. Soruların anlaş1lırlığı ve kültürel uygunluğu da göz önüne alınarak değerlendirmeler yapılmış, taslak bir Türkçe ölçek oluşturulmuştur. Daha sonra Fen eğitimcilerinin ve Kimya öğretim üyelerinin görüşlerine tekrar başvurarak testin son hali ortaya çıkarılmıştır. Testin bu son hali bir Türkçe uzmanının görüşü alındıktan sonra uygulamaya hazır hale gelmiştir.

Örneklem: Bu araştırmanın örneklemini 2015-2016 akademik yılında Ankara'da bir üniversitenin eğitim fakültesinde eğitimine devam eden, 207 öğretmen adayı oluşturmuştur. Öğretmen adaylarına kolay ulaşılabilen durum örneklemesi (convenient sampling) yöntemi ile ulaşılmıştır. Çalışmada öğretmen adaylarının seçilmesinin nedeni hem orijinal testinde öğretmen adaylarından elde edilen veriler ile geçerlik ve güvenirlik çalışmasının yapılmış olması hem de geleceğin öğretmenlerinin atmosferde görülen çevre problemleri ile ilgili kavram yanılgılarının tespitini yapmaktır. Adaylar ortaöğretim kimya ve fizik öğretmenliği ile ilköğretim fen bilgisi öğretmenliği bölümlerinin öğrencileridir. Araştırmaya katılım 
gönüllülük çerçevesinde sağlanmıştır. Çalışmaya katılan öğretmen adaylarının cinsiyete, öğretmenlik dalı ve sınıfa göre dağılımı Tablo 1'de verilmiştir.

Tablo 1. Katılımcıların demografik verilere göre dă̆ılımı

\begin{tabular}{|c|c|c|c|}
\hline Öğretmenlik Dalı & Cinsiyet & Sinıf & Toplam \\
\hline \multirow[t]{3}{*}{ Fizik öğretmenliği } & Kız: 18 & 1. Sinıf: 15 & \\
\hline & Erkek: 32 & 2. Sinıf: 19 & 50 \\
\hline & & 3. Sinif: 17 & \\
\hline \multirow[t]{3}{*}{ Kimya öğretmenliği } & Kız: 34 & 1. Sinif: 20 & \\
\hline & Erkek: 22 & 2. Sinıf: 19 & 56 \\
\hline & & 3. Sinıf: 16 & \\
\hline \multirow[t]{3}{*}{ Fen Bilgisi öğretmenliği } & K1z: 64 & 1. Sinif: 32 & \\
\hline & Erkek: 37 & 2. Sinıf: 31 & 101 \\
\hline & & 3. Sinıf: 38 & \\
\hline \multirow[t]{3}{*}{ Toplam } & K1z: 116 & 1. Sinif: 67 & \\
\hline & Erkek: 91 & 2. Sinif: 69 & 207 \\
\hline & & 3. Sinıf: 71 & \\
\hline
\end{tabular}

Veri toplama aracı: Bu çalışmada Arslan ve diğ, (2012) tarafından geliştirilmiş test kullanılmıştır. Test, atmosferde görülen çevre problemlerinden; sera etkisi, küresel ısınma, ozon tabakasının incelmesi ve asit yağmuru kavramlarının nedenleri, sonuçları ve bu problemlere karşı alınacak önlemleri soran 13 adet üç aşamalı sorudan oluşmaktadır. Testin her bir sorusunun ilk aşaması kavramsal bir soruyu, ikinci aşaması ilk aşamada sorulan soruya verilen cevabın nedenini, üçüncü aşaması ise ilk iki aşamada verilen cevaptan emin olunup olunmadığını içermektedir. İkinci aşamada sunulan nedenler bir doğru kavramsal bilgi ve birinci aşamada listelenen cevapların verilmesine sebep olabilecek kavram yanılgılarından oluşmaktadır. Testte alan yazından ve açık uçlu sorular ile toplanan verilerden elde edilen 33 adet kavram yanılgısı bulunmaktadır. Üçüncü aşamada ise testin her bir sorusuna Hasan, Bagayoko ve Kelley, (1999) ve Pesman ve Eryilmaz, (2010)'1n önerileri doğrultusunda cevaptan emin olma endeksi eklenmiştir. Testin orijinali 256 öğretmen adayına uygulanmış, geçerliği 0.74 (cronbach alpha) ve güçlük endeksi 0.19 olarak raporlanmıştır. (Arslan ve di $\breve{g}, 2012$ ). 
Verilerin Toplanması ve Analizi: Öğretmen adaylarından AÇPTT’yi bireysel olarak ve isimlerini yazmadan cevaplamaları istenmiştir. Katılımcıların AÇPTT'yi tamamlamaları yaklaşık olarak 20-25 dakika sürmüştür. AÇPTT’ye verilen cevaplar muhtemel sekiz farklı kombinasyon şeklinde olabilmektedir (Tablo2).

Tablo 2. AÇPTT sorularının cevap kombinasyonları

\begin{tabular}{llllc}
\hline $\begin{array}{l}\text { Birinci } \\
\text { Aşama }\end{array}$ & $\begin{array}{l}\text { İkinci } \\
\text { Aşama }\end{array}$ & $\begin{array}{l}\text { Üçüncü } \\
\text { Aşama }\end{array}$ & \multicolumn{1}{c}{ Kategoriler } & Frekans \\
\hline Doğru & Doğru & Emin & Bilimsel Bilgi & 42,46 \\
\hline Doğru & Yanlış & Emin & Kavram Yanılgısı (yanlış sebepli doğru) & 4,77 \\
\hline Yanlış & Doğru & Emin & Kavram Yanılgısı (doğru sebepli yanlış) & 3,08 \\
\hline Yanlış & Yanlış & Emin & Kavram Yanılgısı & 5,61 \\
\hline Doğru & Doğru & Emin Değil & Şanslı Tahmin / Güven eksikliği & 8,15 \\
\hline Doğru & Yanlış & Emin Değil & Bilgi eksikliği & 35,92 \\
\hline Yanlış & Doğru & Emin Değil & Bilgi eksikliği & \\
\hline Yanlış & Yanlış & Emin Değil & Bilgi eksikliği & \\
\hline
\end{tabular}

*Not. Arslan ve diğ, (2012)'den adapte edilmiştir. Frekans sütunu uygulama sonuçlarına göre her bir kategoriye düşen öğrenci yüzdeliklerini göstermektedir.

Elde edilen veriler MS Excel programında doğru cevaplar 1, yanlış cevaplar 0 olacak şekilde kodlanarak her öğrenci için sekiz farklı puan oluşturulmuştur (Pesman ve Eryilmaz, 2010). Sorunların yalnızca ilk aşamasına verilen cevapların kodlanması ile elde edilen puanlar (birinci aşama puanları-BAP), birinci ve ikinci aşamalarının her ikisine verilen cevapların kodlanması ile ilde edilen puanlar (her iki aşama puanları-HAP), soruların her üç aşamasına da verilen cevapların birlikte kodlandığı puanlar (toplam puan-TP), emin olma endeksi puanları (EEP), bilgi eksikliği puanları (BEP) şeklinde isimlendirilmiştir. Ayrıca katılımcıların cevapları kavram yanılgıları boyutundan da incelenmiş ve soruların yalnızca birinci aşamalarında kavram yanılgısını işaretleyenlerin 1 , diğerlerinin 0 olarak kodlanması ile elde edilen kavram yanılgısı-1 puanları (KY-1), hem birinci hem de ikinci aşamada 
kavram yanılgısını işaretleyenlerin 1 diğerlerinin $O$ olarak kodlanması ile elde edilen kavram yanılgısı-2 puanları (KY-2) ve aynı zamanda bu kavram yanılgılarından emin olanların kodlandığı kavram yanılgısı-3 puanları (KY-3) elde edilmiştir. Son olarak oluşturulan puanlar Statistical Package for the Social Sciences (SPSS) programı kullanılarak madde istatistikleri (ortalama, standart sapma, varyans), ölçek istatistikleri (güvenirlik, güçlük indeksi, ayırt edicilik indeksi) ve toplam puanlar ile katılımcıların emin olma durumlarının korelasyon katsayısı hesaplanmıştır.

\section{Bulgular}

Toplam puanlar kullanılarak yapılan betimleyici istatistikler Tablo 3'te verilmiştir. AÇPTT’nin güvenirlik katsayısı cronbach alpha hesaplanarak bulunmuştur.

Tablo 3. AÇPTT toplam puanlarının betimleyici istatistikleri

\begin{tabular}{lc}
\hline Madde sayı1s1 & 13 \\
\hline Kat1lımcı Sayıs1 & 207 \\
\hline Ortalama & 2.86 \\
\hline Standart sapma (SD) & 2.54 \\
\hline Varyans & 6.44 \\
\hline Minimum & 0 \\
\hline Maksimum & 12 \\
\hline Cronbach alpha & 0.57 \\
\hline \multicolumn{1}{c}{ Tek aşamalı test } & 0.68 \\
\hline \multicolumn{1}{c}{ İki a̧samalı test } & 0.73 \\
\hline \multicolumn{1}{c}{ Üç aşamalı test } &
\end{tabular}

Testin yalnızca tek aşamalı sorulardan oluştuğu düşünülerek cronbach alpha hesaplandığında 0.57, ilk iki aşama kullanılarak hesaplandığında 0.68 , her üç aşamaya verilen cevaplar puanlanarak elde edilen toplam puanlar ile hesaplandığında ise 0.73 bulunmuştur. Bu değer testin orijinal versiyonunun uygulanması ile elde edilen değere (0.74) çok yakındır ve kriter referanslı testler için kabul edilebilir aralıktadır (Büyüköztürk, 2011). 
AÇPTT'yi oluşturan her bir soru için yapılan madde güçlük ve ayırt edicilik indeksleri Tablo 4'de görülmektedir.

Tablo 4. Madde istatistikleri ve testin ortalama güçlüğü

\begin{tabular}{ccc}
\hline Madde No & Madde Güçlük İndeksi (p) & Madde Ayırtedicilik İndeksi (r) \\
\hline 1 & 0.21 & 0.36 \\
\hline 2 & 0.37 & 0.43 \\
\hline 3 & 0.19 & 0.45 \\
\hline 4 & 0.15 & 0.35 \\
\hline 5 & 0.12 & 0.29 \\
\hline 6 & 0.25 & 0.52 \\
\hline 7 & 0.47 & 0.59 \\
\hline 8 & 0.26 & 0.65 \\
\hline 9 & 0.15 & 0.50 \\
\hline 10 & 0.29 & 0.55 \\
\hline 11 & 0.11 & 0.54 \\
\hline 12 & 0.15 & 0.54 \\
\hline 13 & 0.15 & 0.51 \\
\hline Ortalama & 0.22 & 0.48 \\
\hline
\end{tabular}

Buna göre madde güçlüklerinin ortalaması 0.22 bulunmuş ve her madde için güçlük 0.11 ile 0.47 arasında değişen düşük değerler almıştır. Madde güçlüğü sorulara doğru cevap verenlerin yüzdesi olduğu için bir testin ortalama madde güçlüğü 0.30 değerinden daha küçük olduğunda test zor bir test olarak ifade edilir. Madde güçlüğü AÇPTT’nin yalnızca birinci aşama soruları ile hesaplandığında 0.45 , iki aşama bir arada hesaplandığında ise 0.35 olarak bulunmaktadır. Bu beklenen bir sonuçtur çünkü yalnızca bir soruya doğru cevap vermek ile verilen cevabın nedeninin sorgulandığı ikinci soruya da doğru cevap vermek üstelik bu cevaplardan emin olmak elbette ki aynı güçlükte değildir. Testin güçlük endeksi tek aşamalı (çoktan seçmeli) testlerle kıyaslandığında oldukça düşük görünmekte ancak bu durum üç aşamalı testlerin doğasından kaynaklanmaktadır. Testin üç aşamalı olması sayesinde hem tahmine dayalı olarak verilen doğru cevap yüzdeleri azalmakta hem de kavram yanılgısı 
yüzdeleri düşmektedir. Böylelikle yanlış cevapların nedeni daha net olarak ortaya çıkmakta ve bilgi eksikliği yüzdeleri yükselmektedir. Alan yazındaki diğer üç aşamalı test çalışmaları (Caleon ve Subramaniam, 2010; Pesman ve Eryilmaz, 2010; Taslidere, 2016) incelendiğinde benzeri şekilde düşük güçlük değerlerinin sunulduğu görülmüştür.

Tablo 4'e göre 11 numaralı madde öğrencilere göre en zor olandır $(\mathrm{p}=0.11)$, yani öğretmen adaylarının sadece $\% 11 \mathrm{i}$ bu soruya doğru cevap, $\% 89$ u ise yanlış cevap vermiştir. maddenin içeriği incelendiğinde asit yağmurlarının doğru ifade edilişi sorgulanmaktadır. $\mathrm{Bu}$ soru yaygın bir kavram yanılgısı olan sera gazlarının ozonu tabakasının incelmesine neden olduğu görüşünü içermektedir. Diğer sorularında güçlük değerleri incelendiğinde 7 numaralı sorunun öğretmen adaylarına en kolay (0.47) geldiği gözlenmektedir. Neredeyse örneklemin yarısı soruya doğru cevap vermiştir. Bu soru ise ozon tabakasının yapısı ile ilgilidir.

Madde ayırt edicilik indeksi +1 ile -1 arasında değerler alabilir ve madde skoru ile toplam test skoru arasındaki korelasyonu ifade eder. Bu korelasyonun orta derecede yani 0,30 ile 0,80 aralığında olması ise testi oluşturan maddelerin katılımcıların bilgi seviyelerini ayırt etmede başarılı olduğunun göstergesi olarak kabul edilir (Wendler ve Walker, 2006). Bu çalışmada test maddelerinin ayırt edicilik indeksleri 0.29 (madde 5) ve 0.65 (madde 8) aralığında hesaplanmıştır. Bu sonuç testten çıkartılmayı gerektirecek madde olmadığının göstergesidir. Bunlara ek olarak, testin orijinalinin (İngilizce) ayırt edicilik ortalaması 0.38 iken Türkçeye uyarlanmış versiyonda bu değer 0.48 olarak hesaplanmıştır.

AÇPTT’nin kapsam ve yapı geçerliliği bulguları da uyarlanma sürecinde incelenmiştir. Hestenes ve Halloun (1995), kapsam geçerliliğine kanıt olarak yanlış sebepli doğru ve doğru sebepli yanlışların yüzdelerinin hesaplanmasını önermiştir. Hestenes ve Halloun (1995)'a göre eğer test açık ve anlaş1lır ise, bilgili katılımcılar soruları doğru 
cevaplayacaktır ve bu nedenle yanlış sebepli doğru ve doğru sebepli yanlış ihtimali en aza indirgendiğinde çoktan seçmeli bir testin kapsam geçerliliği desteklenmiş olmaktadır. Buna ek olarak, yanlış sebepli doğru elde etme ihtimalinin \%10 da küçük olması gerektiği belirtilmiştir. Mevcut uyarlama çalışmasında yanlış sebepli doğrular \%4.77 iken, doğru sebepli yanlışlar \%3.08'dir.

Bir testin yapı geçerliliğinin belirlenmesi için korelasyon ve faktör analizi gibi testin iç yapısını inceleyen istatistiksel analizler gerekmektedir. Cataloğlu (2002)'na göre yüksek puanlarla emin olma puanı arasındaki korelasyon yapı geçerliliğinin bir kanıtıdır. Yüksek puan alan bireylerin cevaplarından emin olma durumunun düşük puan alanlara göre daha yüksek olması beklenir. Bu korelasyonun yüksek olması testin maddelerinin işlevselliğinin göstergesidir. Özgün çalışmada olduğu gibi adaptasyon çalışmasında da, soruların her üç aşamasına da verilen cevapların birlikte kodlandığı puanlar (toplam puan-TP) ile emin olma endeksi puanları (EEP) arasındaki korelasyon incelenmiştir. Sonuçlar p 0.01, noktasında istatistiksel olarak pozitif anlamlı bir korelasyon (0.40) olduğunu göstermiştir. Bu değer testin yapı geçerliliği için kanıt teşkil etmektedir. Öğretmen adaylarının toplam puanları üzerinden açıklayıcı bir faktör analizi yapılsa da anlamlı faktörler oluşmamıştır. Bu durumun muhtemel nedeni testin sadece atmosferle ilgili küresel problemlere (küresel 1sınma, sera etkisi, ozon tabakasının incelmesi ve asit yağmurları) değil, aynı zamanda bu problemleri doğası- neden-sonuç ilişkisi içerisinde incelemesi olabilir.

AÇPTT’nin madde istatistikleri dışında, her maddenin çeldiriciler bazında analizleri de incelenmiştir. $\mathrm{Bu}$ bulgular, öğretmen adaylarının birinci, ikinci ve üçüncü aşamalara verdikleri yanıtların birlikte incelenmesine dolayısı ile çalışmaya katılanların kavramsal bilgileri hakkında çıkarımlar yapılmasına olanak sağlamıştır. Tablo 5 te bir numaralı 
maddenin birinci, ikinci ve üçüncü aşamasına verilen cevaplarının seçeneklere dağılımının yüzdelerini göstermektedir.

Tablo 5. Birinci maddeye verilen cevapların seçeneklere dăğllımı

\begin{tabular}{|c|c|c|c|c|c|c|c|c|c|c|c|c|}
\hline & \multicolumn{12}{|c|}{ İkinci Aşama } \\
\hline & & \multicolumn{2}{|c|}{$\mathbf{A}$} & \multicolumn{2}{|c|}{ B } & \multicolumn{2}{|c|}{ C } & \multicolumn{2}{|c|}{ D } & \multicolumn{2}{|c|}{$\mathbf{E}$} & \\
\hline & & \multicolumn{2}{|c|}{$\begin{array}{l}\text { Üçüncü } \\
\text { Aşama }\end{array}$} & \multicolumn{2}{|c|}{$\begin{array}{l}\text { Üçüncü } \\
\text { Aşama }\end{array}$} & \multicolumn{2}{|c|}{$\begin{array}{l}\text { Üçüncü } \\
\text { Aşama }\end{array}$} & \multicolumn{2}{|c|}{$\begin{array}{l}\text { Üçüncü } \\
\text { Aşama }\end{array}$} & \multicolumn{2}{|c|}{$\begin{array}{l}\text { Üçüncü } \\
\text { Aşama }\end{array}$} & \\
\hline & & Emin & $\begin{array}{l}\text { Emin } \\
\text { Değil }\end{array}$ & Emin & $\begin{array}{l}\text { Emin } \\
\text { Değil }\end{array}$ & Emin & $\begin{array}{l}\text { Emin } \\
\text { Değil }\end{array}$ & Emin & $\begin{array}{l}\text { Emin } \\
\text { Değil }\end{array}$ & Emin & $\begin{array}{l}\text { Emin } \\
\text { Değil }\end{array}$ & Toplam \\
\hline \multirow{3}{*}{ 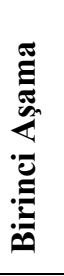 } & $\mathbf{A}$ & $\begin{array}{c}12 \\
(5.8)\end{array}$ & $\begin{array}{c}11 \\
(5.3)\end{array}$ & $\begin{array}{c}29 \\
(14.1)\end{array}$ & $\begin{array}{c}19 \\
(9.2)\end{array}$ & $\begin{array}{c}5 \\
(2.4)\end{array}$ & $\begin{array}{c}4 \\
(1.9)\end{array}$ & $\begin{array}{c}1 \\
(0.5)\end{array}$ & $\begin{array}{c}3 \\
(1.5)\end{array}$ & $\begin{array}{c}1 \\
(0.5)\end{array}$ & $\begin{array}{c}1 \\
(0.5)\end{array}$ & $\begin{array}{c}86 \\
(41.7)\end{array}$ \\
\hline & B & $\begin{array}{c}5 \\
(2.4)\end{array}$ & $\begin{array}{c}7 \\
(3.4) \\
\end{array}$ & $\begin{array}{c}6 \\
(2.9) \\
\end{array}$ & $\begin{array}{c}9 \\
(4.4) \\
\end{array}$ & $\begin{array}{c}43 * \\
(20.9) \\
\end{array}$ & $\begin{array}{c}31 \\
(15.1)\end{array}$ & $\begin{array}{c}8 \\
(3.9) \\
\end{array}$ & $\begin{array}{c}6 \\
(2.9) \\
\end{array}$ & $\begin{array}{c}4 \\
(1.9) \\
\end{array}$ & $\begin{array}{c}1 \\
(0.5)\end{array}$ & $\begin{array}{c}120 \\
(58.3) \\
\end{array}$ \\
\hline & Toplam & $\begin{array}{c}17 \\
(8.2) \\
\end{array}$ & $\begin{array}{c}18 \\
(8.7) \\
\end{array}$ & $\begin{array}{c}35 \\
(17.0) \\
\end{array}$ & $\begin{array}{c}28 \\
(13.6) \\
\end{array}$ & $\begin{array}{c}48 \\
(23.3) \\
\end{array}$ & $\begin{array}{c}35 \\
(17.0) \\
\end{array}$ & $\begin{array}{c}9 \\
(4.4) \\
\end{array}$ & $\begin{array}{c}9 \\
(4.4) \\
\end{array}$ & $\begin{array}{c}5 \\
(2.4) \\
\end{array}$ & $\begin{array}{c}2 \\
(1.0) \\
\end{array}$ & $\begin{array}{c}206 \\
(100) \\
\end{array}$ \\
\hline
\end{tabular}

Not. Hücrelerdeki rakamlar, satır ve sütunların çakıştı̆̆ şekilde cevap veren öğrenci sayısını, parantez içindeki rakamlar ise bu sayıların yüzdeliklerini ifade etmektedir.* Doğru cevap, doğru neden ve emin olma durumunu belirtmektedir.

Bir numaralı AÇPTT maddesi küresel 1sınma olayını sorgulatmaktadır. Bu maddenin birinci aşamasının A seçeneğinde, küresel 1sınma 'Ozon tabakasının incelmesi ile atmosfer ısısının artı̧ıdır' şeklinde tanımlanırken B seçeneğinde 'Sera gazları etkisiyle atmosferin ısısının periyodik olarak artmasıdır' biçiminde tanımlanmıştır. $\mathrm{Bu}$ sorunun 1. aşaması öğretmen adaylarının küresel ısınma ile ilgili en yaygın kavram yanılgılarından biri olan 'ozon tabakasının incelmesi ile atmosfer ısısının artışıdır' ifadesini içermektedir, bu yanılgı alan yazında da sıklıkla belirtilmiştir (Michail ve diğ., 2007; Summers ve diğ., 2000). A seçeneği öğrencilerin \%41.7'si tarafindan seçilirken, B seçeneği \%58.3 tarafindan işaretlenmiştir. 
Aynı sorunun ikinci aşaması incelendiğinde A dan E ye kadar beş tane çeldirici olduğu görülmekte ve doğru cevap olan C seçeneğinin en fazla işaretlendiği görünmektedir. Emin olma ve emin olmama durumu birlikte ele alındığında doğru cevabın öğretmen adaylarının \%36'sı tarafından işaretlendiği görünmektedir. Her üç aşama birlikte incelendiğinde birinci aşamaya doğru cevap (B) verip, ikinci aşamada doğru cevap (C) seçip bu durumdan emin olan katılımcıların oranı \%20.9'dur. Bu alternatif en yakın yüzde değeri alan durum doğru-doğru seçip emin olmama durumudur (\%15.1). Aynı şekilde kavram yanılgısı içeren seçenekler de her üç aşama dikkate alınarak incelendiğinde birinci aşamaya ozon tabakasının incelmesi ile atmosfer ısısının artışı olduğu şeklindeki cevap (A) seçip, ikinci aşamada ise bu kavram yanılgısını açıklayan cevap (B)'yi seçen ve bu durumdan emin olan katılımcılar 29 kişi (\%14.1)'dir. Aynı soruda aynı seçenekleri seçmesine rağmen emin olmayan 19 kişi vardır. Bu rakamlar doğru kavramsal bilgiye sahip olunsa da bilgiden emin olma durumunun ne kadar önemli olduğunu göstermektedir. Tüm maddelere verilen cevapların seçeneklere dağılım yüzdeleri hesaplanmış, çeldiricilerin etkili olup olmadığı belirlenmiştir. $\mathrm{Bu}$ analizler testin maddeleri hatta çeldiricileri bazında kapsadığı kavramsal bilginin yorumlanmasına olanak sağlamıştır.

\section{Tartışma ve Sonuç}

Atmosfer ile İlişkili Çevre Problemleri Tanı Testi’nin (AÇPTT) dilimize uyarlanmasını sağlayan bu çalışma AÇPTT’nin geçerli ve güvenilir bir ölçüm aracı olduğunu ortaya çıkarmıştır. Testin güvenirliğine ilişkin hesaplanan Cronbach alfa katsayısı $(\alpha)$ 0.73'dür. Güvenirlik katsayısı 0.70 ve üzerinde olan testler, test puanlarının güvenirliği için yeterli görülmektedir (Büyüköztürk, 2011; Crocker ve Algina, 2008). Dolayısıyla AÇPTT, Türkiye'deki öğretmen adaylarının küresel 1sınma, sera etkisi, ozon tabakası incelmesi ve asit 
yağmurları konularındaki kavram yanılgılarını değerlendirmek için güvenilir bir ölçme aracı olarak kullanılabilir. Testin doğası gereği, eksik bilinen kavramlar ile yanlış bilinen kavramlar birbirinden ayırt edilebilecektir. AÇPTT sadece öğretmen adaylarına değil, aynı zamanda lise öğrencilerine ve aktif öğretmenlere uygulanabilecek düzeyde bir tanı testidir.

Testin betimsel analizleri incelendiğinde, öğretmen adaylarının ölçeğin genelinden aldıkları ortalama puanın 2.86 olduğu görülmektedir. Alınabilecek en yüksek puanın 13 olduğu göz önünde bulundurulduğunda, orijinalinde olduğu gibi öğretmen adaylarının sera etkisi, küresel ısınma, ozon tabakasının incelmesi ve asit yağmurları konularında yetersiz bilgiye sahip oldukları söylenebilir (Arsal, 2010; Çimer, Çimer ve Ursavaş, 2011; Daskolia, Flogaitis ve Papageorgiou, 2006; Gungordu, Yalcın-Celik, ve K1lıc, 2017; Khalid, 2001; 2003; Oskay, Temel, Özgür ve Erdem, 2012; Pabuçcu; 2016). AÇPTT’nin özgün versiyonunda olmadığı gibi uyarlanmış versiyonunda da alt boyutları yoktur. Kapsadığı konuların çeşitliliği, bu konuları doğası-nedeni-sonucu bağlamında incelemesi ve o konudaki emin olma durumunu irdelemesi testin keskin alt boyutlara ayrılmasına imkân vermemektedir. Testin özgün versiyonunu geliştiren araştırmacılar tarafından dilimize uyarlanması sonuçların güvenilirliğini desteklemektedir.

Farklı kitle iletişim araçlarından sıklıkla duyulan atmosfer ile alakalı çevre problemleri hakkında öğretmen adaylarının doğru ya da alternatif bilgiye sahip olmaları bu konuda tanı testi geliştirilmesini gerektirir. AÇPTT’nin dilimize uyarlanması, uygun tanının konmasında ve tanıya uygun programlarının hazırlanmasında oldukça önemli bir ihtiyacı karşılama potansiyeline sahiptir. Ülkemizde çevre problemleri ile ilgili yapılan çalışmalar betimsel boyutta sınırlı kalmamıştır ve bu test sayesinde çevre problemleri konularında çalışan araştırmacılarımız uluslararası geçerliliği ve güvenilirliği olan bir testi kendi dilimizde 
lise ve üstü her seviyede kullanabilecektir. Ayrıca, bulgular doğrultusunda araştırmacılar, mevcut öğretim yöntem ve/ya modellerini güncelleyip testin kapsadığı yanılgıları giderecek şekilde düzenleyebilirler.

\section{Makalenin Bilimdeki Konumu (Yeri)}

Fen Bilgisi Eğitimi/ Çevre Eğitimi

\section{Makalenin Bilimdeki Özgünlüğü}

Dilimizde hazırlanmış üç aşamalı atmosfer ile alakalı çevre problemleri (sera etkisi, küresel ısınma, ozon tabakasının incelmesi ve asit yağmurları) kavramlarını içeren tanı testi olmadığı için bu çalışma ülkemiz araştırmacıları tarafından kullanılabilecek özgünlüktedir ve bu ihtiyacı giderme potansiyeline sahiptir. Bu makale ile Türkçeye uyarlanan Atmosfer ile ilgili çevre problemleri tanı testi (AÇPTT) lise ve üstü katılımcıların küresel 1sınma, sera etkisi, ozon tabakası incelmesi ve asit yağmurları gibi konularda kavram yanılgılarına sahip olma durumunu bilgi eksikliğinden ayırt edebilmeyi tanımlar. Bu doğrultuda uygun öğretim yöntemleri tasarlanarak anlamlı öğrenme ortamları oluşmasını destekler. $\mathrm{Bu}$ makale ile geliştirilen testin yaptığı tanılamayı yapacak yerli bir tanı testi yoktur. Pek çok ulusal araştırmacı, bu makalede uyarlanan atmosfer ile ilgili çevre problemleri tanı testini (AÇPTT) testi geliştiren araştırmacılardan kendi çalışmalarında kullanmak üzere istemiştir. Bunun yanında küresel problemlere duyarsız kalamayacağımız da düşünülürse böyle bir testin dilimize uyarlanmaması bu kavramların nasıl özümsendiği konusunda kesin tanı koymamamız konusunda sıkıntılar/eksiklikler doğurur.

$\mathrm{Bu}$ makale ile uyarlanan atmosfer ile ilgili çevre problemleri tanı testi (AÇPTT) katılımcıların bu konulardaki kavram yanılgılarını tespit eder ve bu konulardaki bilgi 
eksikliklerini belirler. Çevre Eğitimi ile ilgili çalışan bilim insanlarını ve çevre konularına meraklı öğretmen ve öğretmen adaylarını ilgilendirecek bir çalışmadır.

\section{Kaynaklar}

Amin, T. G., Smith, C., ve Wiser, M. (2015). Student conceptions and conceptual change. Handbook of research on science education, 57-81.

Arsal, Z. (2010). The greenhouse effect misconceptions of the elementary school teacher candidates. Elementary Education Online, 9(1), 229-240.

Arslan, H. O., Cigdemoglu, C. ve Moseley C. (2012). A Three-Tier Diagnostic Test to Assess Pre-Service Teachers' Misconceptions about Global Warming, Greenhouse Effect, Ozone Layer Depletion, and Acid Rain, International Journal of Science Education, 34(11), 1667-1686.

Ayvacı, H. Ş. ve Çoruhlu, T. Ş. (2009). Öğrencilerin küresel çevre sorunlarına bakışları ve kavram yanılgılarının belirlenmesine yönelik gelişimsel bir araştırma. Hasan Ali Yücel Eğitim Fakültesi Dergisi, 6(2), 11-25.

Boyes, E., Chambers, W. ve Stanisstreet, M. (1995). Trainee primary teachers' ideas about the ozone layer. Environmental Education Research, 1(2), 133-145.

Bozkurt,O. ve Aydoğdu, M. (2004). İlköğretim 6. 7. ve 8. sınıf öğrencilerinin 'Ozon tabakas1 ve görevleri' hakkındaki kavram yanılgıları ve oluşturma şekilleri, Kastamonu Ĕgitim Dergisi, 12(2), 369-376. 
Bozkurt, O. ve Cansüngü Koray, Ö. (2002). İlköğretim öğrencilerinin çevre eğitiminde sera etkisi ile ilgili kavram yanılgıları. Hacettepe Üniversitesi Ĕ̆itim Fakültesi Dergisi, 23, $67-73$.

Büyüköztürk, Ş. (2011). Sosyal Bilimler Iç̧in Veri Analizi El Kitabı. Ankara: Pegem Akademi.

Caleon, I. ve Subramaniam, R. (2010). Development and application of a three-tier diagnostic test to assess secondary students' understanding of waves. International Journal of Science Education, 32(7), 939-961.

Cataloglu, E. (2002). Development and validation of an achievement test in introductory quantum mechanics: The Quantum Mechanics Visualization Instrument (QMVI), Yayınlanmamış Doktora Tezi, The Pennsylvania State University, USA.

Clement, J., Brown, D.E. ve Zietsman, A. (1989). Not all preconceptions are misconceptions: Finding 'anchoring conceptions' for grounding instruction on students' intuition. International Journal of Science Education, 11, 554-565.

Crocker, L., ve Algina, A. (2008). Introduction to classical and modern test theory. Mason, Ohio: Cengage Learning.

Çimer, S. O., Çimer, A. ve Ursavas, N. (2011). Student teachers' conceptions about global warming and changes in their conceptions during pre-service education: A cross sectional study. Educational Research and Reviews, 6(8), 592-597.

Darçın, E. S., Bozkurt, O., Hamalosmanoğlu, M. ve Köse, S. (2006). Misconceptions About Greenhouse Effect. International Journal of Environmental and Science Education, l(2), 104-115. 
Daskolia, M., Flogaitis, E. ve Papageorgiou, E. (2006). Kindergarten teachers' conceptual framework on the ozone layer depletion. Exploring the associative meanings of a global environmental issue. Journal of Science Education and Technology, 15(2), 168-177.

Dawson, V., and K. Carson. 2013. Australian secondary school students' understanding of climate change. Teaching Science 59(3), 9-14.

Dove, J. (1996). Student teacher understanding of the greenhouse effect, ozone layer depletion and acid rain. Environmental Education Research, 2(1), 89-100.

Driver, R. (1988). Changing conceptions. Tijdschrift voor Didactie der. $\beta$-Wetenschappen, 6(3), 161-198.

Driver, R. ve Easley, J. (1978). Pupils and Paradigms: A review of literature related to concept development inadolescent science students. Studies in Science Education, 5, 61-84.

Duit, R., \& Treagust, D. F. (2012). How can conceptual change contribute to theory and practice in science education? In Second international handbook of science education (pp. 107-118). Springer Netherlands.

Enerji ve Tabii Kaynaklar Bakanlığı, (2012). İklim Değişikliği Nedir? http://www.eie.gov.tr/iklim_deg/i_deg_nedir.aspx adresinden alınmıştır.

Eryılmaz, A. (2010). Development and application of three-tier heat and temperature test: Sample of bachelor and graduate students. Egitim Arastirmalari - Eurasian Journal of Educational Research, 40, 53-76. 
Gowda, M. R., Fox, J. C. ve Magelky, R. D. (1997). Students' understanding of climate change: Insights for scientists and educators. Bulletin of the American Meteorological Society, 78(10), 2232-2240.

Groves, F.H. ve Pugh, A.F. (1999). Elementary pre-service teacher perceptions of the greenhouse effect. Journal of Science Education and Technology, 8(1), 75-81.

Groves, F.H. ve Pugh, A.F. (2002). Cognitive illusions as hindrances to learning complex environmental issues. Journal of Science Education and Technology, 11(4), 381-390.

Gungordu, N., Yalcın-Celik, A. \& K1lic, Z. (2017). Stundets' misconceptions about the ozone layer and the effect of Internet based media on it. International Electronic Journal of Environmental Education, 7(1), 1-15.

Hammer, D. (1996). More than misconceptions: Multiple perspectives on student knowledge and reasoning, and an appropriate role for education research. American Journal of Physics, 64, 1316-1325.

Hasan, S., Bagayoko, D. ve Kelley, E.L. (1999). Misconceptions and the certainty of response index (CRI). Physics Education, 34(5), 294-299.

Helm, H., (1980). Misconceptions in Physics Amongst South African Students. Physics Education, 15, 92-105,

Hestenes, D. ve Halloun, I. (1995). Interpreting the force concept inventory. Physics Teacher, $33,502-506$.

Hungerford, H. R., Peyton, R. B. ve Wilke, R. (1980). Goals for curriculum development in environmental education. The Journal of Environmental Education, 11(3), 42-47 
Kara, F. (2015). Knowledge Level of Prospective Science Teachers Regarding Formation and Effects of Acid Rains on the Environment and Organisms. International Journal of Applied Science and Technology, 5(4), 128-131.

Karpudewan, M., Roth, W.M. ve Chandrakesan, K. (2015). Remediating misconception on climate change among secondary school students in Malaysia. Environmental Education Research, 21(4), 631-648.

Khalid, T. (2001). Pre-service teachers' misconceptions regarding three environmental issues. Canadian Journal of Environmental Education, 6, 102-120.

Khalid, T. (2003). Pre-service high school teachers' perceptions of three environmental phenomena. Environmental Education Research, 9(1), 35-50.

Kirbulut, Z. D., \& Geban, O. (2014). Using Three-Tier Diagnostic Test to Assess Students' Misconceptions of States of Matter. Eurasia Journal of Mathematics, Science \& Technology Education, 10(5), 509-521.

Kışoğlu, M., Gürbüz, H., Erkol, M., Akar, M. S. ve Akıllı, M. (2010). Prospective Turkish elementary science teachers' knowledge level about the greenhouse effect and their views on environmental education in university. International Electronic Journal of Elementary Education, 2(2), 217-236.

Michail, S., Stamou, A.G. ve Stamou, G.P. (2007). Greek primary school teachers understanding of current environmental issues: An exploration of their environmental knowledge and images of nature. Science Education, 91(2), 244-259.

Novak, J.D. (1990). Concept Mapping, A useful tool for science education. Journal of Research in Science Teaching, 27, 937-949. 
Oskay, Ö. Ö., Temel, S., Özgür, S. D., ve Erdem, E. (2012). Determination of preservice chemistry teachers' cognitive structures via flow map method and their knowledge level on "greenhouse gases and their effects" topic. Eurasian Journal of Physics \& Chemistry Education, 4(1), 30-45.

Pabuçcu, Aybüke. (2016). Öğretmen adaylarının asit yağmurlarıyla ilgili bilgilerinin kimya okur-yazarlığı açısından incelenmesi. Abant İzzet Baysal Üniversitesi Ĕgitim Fakültesi Dergisi, 16(3), 961-976.

Pekel, F.O., Kaya, E. ve Demir, Y. (2007). Farklı lise öğrencilerinin ozon tabakasına ilişkin düşüncelerinin karşılaştırılması, Kastamonu Eğitim Dergisi, 15(1), 169-174.

Pesman, H. ve Eryilmaz, A. (2010). Development of a three-tier test to assess misconceptions about simple electric circuits. The Journal of Educational Research, 103, 208-222.

Posner, G.J., Strike, K.A., Hewson, P.W. ve Gertzog, W.A. (1982). Accommodation of a scientific conception: Toward a theory of conceptual change. Science Education, 66, 211-227.

Saat, R. M., Fadzil, H. M., Aziz, A., Azlina, N., Haron, K., Rashid, K. A., \& Shamsuar, N. R. (2016). Development of an online three-tier diagnostic test to assess pre-university students' understanding of cellular respiration. Journal of Baltic Science Education, 15(4), 532-546.

Shepardson, D., Niyogi, D., Choi, S. ve Charusombat, U. (2009). Seventh grade students' conceptions of global warming and climate change. Environmental Education Research, 15, 549-570. 
Shepardson, D. P., Niyogi, D., Roychoudhury, A., ve Hirsch, A. (2012). Conceptualizing climate change in the context of a climate system: implications for climate and environmental education. Environmental Education Research, 18(3), 323-352.

Stokes, E., Edge, A. ve West, A. (2001). Environmental educaion in the educational systems of the European Union: Synthesis report. London School of Economics and Political Science, Centre for Educational Research.

Summers, M., Kruger, C., Childs, A. ve Mant, G. (2000). Primary school teachers' understanding of environmental issues: An interview study. Environmental Education Research, 6(4), 293-312.

Sutton, C.R., (1980). The Learner's Prior Knowledge: A Critical Review of Techniques for Probing Its Organization. European Journal of Science Education, 2, 107- 120.

Taber, F. ve Taylor, N. (2009). Climate of Concern--A Search for Effective Strategies for Teaching Children about Global Warming. International Journal of Environmental and Science Education, 4(2), 97-116.

Taslidere, E. (2016). Development and use of a three-tier diagnostic test to assess high school students' misconceptions about the photoelectric effect. Research in Science \& Technological Education, 34(2), 164-186.

Treagust, D.F. (1988). Development and use of diagnostic tests to evaluate students' misconceptions in science. International Journal of Science Education, 10, 159-170.

Vosniadou, S. (Ed.). (2008). International handbook of research on conceptual change. New York: Routledge. 
West, L. ve Pines, A. (1985). Cognitive structure and conceptual change. Orlando, FL: Academic Press.

Wendler, C. L., ve Walker, M. E. (2006). Practical issues in designing and maintaining multiple test forms for large scale programs. S.M. Downing ve T.M. Haladyna (Ed.), Handbook of test development içinde (s.445-467). Mahway NJ: Lawrence Erlbaum.

\section{Ek A}

\section{Küresel Çevre Problemleri Tanı Testi}

Bu testte toplam 13 soru vardır. Her bir soru 3 aşamadan oluşmaktadır. Lütfen tüm soruları dikkatlice okuyunuz, seçeneklerden sadece birini işaretleyiniz. İkinci aşamanın seçenekleri arasında kendi cevabınızı bulamazsanız, noktalı bırakılan yere cevabınızı yazınız.

1.1. Küresel ısınma olarak adlandırılan olay,

a. Ozon tabakasının incelmesi ile atmosfer isısının artısıdır.

b. Sera gazları etkisiyle atmosferin ısısının periyodik olarak artmasıdır.

1.2. Yukarıda verdiğim cevabın sebebi;

a. Dünyaya normalinden daha fazla ultraviyole (UV) 1şınının gelmesi ile dünyanın ısınmasıdır.

b. Ozon tabakasının incelmesi nedeniyle güneşin zararlı ışıllarının dünya yüzeyine gelmesidir.

c. Atmosferdeki karbondioksit $\left(\mathrm{CO}_{2}\right)$ ve metan $\left(\mathrm{CH}_{4}\right)$ gibi gazların doğal konsantrasyonlarının bozulmasıdır.

d. Zararlı kimyasalların normalden daha çok güneşışınını dünya yüzeyine çekmesidir.

1.3. Yukarıdaki iki soruya verdiğim cevaptan;

a. Eminim.

b. Emin değilim.

2.1. Aşağıdakilerden hangisi küresel ısınmanın sonuçlarından birisi olabilir?
a. Kurakl1k
b. Cilt kanseri
c. Asit yağmuru

2.2. Yukarıda verdiğim cevabın sebebi;

a. Küresel ısınma nedeniyle dünyaya daha sık asit yağmuru yağacak olmasıdır.

b. Küresel ısınma ile daha fazla güneş ışını geleceği için cilt kanserlerinde artış olacak olmasıdır.

c. Küresel ısınma artıkça, dünyanın daha fazla çölleşecek olmasıdır.

d.

2.3. Yukarıdaki iki soruya verdiğim cevaptan;
a. Eminim
b. Emin değilim.

3.1. Aşağıdaki cümlelerden hangisi sera etkisi olarak isimlendirilen olayı tanımlamaktadır?

a. Atmosferde bulunan çeşitli gazların dünyadan yansıyan ışınları absorbe etmesidir.

b. Sera etkisi aslında doğal olmayan bir süreçtir. 
c. Sera etkisine sadece insanların aktivitelerinden kaynaklanan karbondioksit $\left(\mathrm{CO}_{2}\right)$ neden olur.

3.2. Yukarıda verdiğim cevabın sebebi;

a. Sera etkisi temelde sadece atmosferdeki karbondioksit $\left(\mathrm{CO}_{2}\right)$ konsantrasyonunun artmasıdır.

b. Sera etkisi atmosferde bulunan sera gazlarının dünyadan geri yansıyan uzun dalga boylu ışınları tutmasıdır.

c. Sera etkisi sanayi devriminden sonra meydana gelmiştir ve tamamen yapay bir olaydır.

d.

3.3. Yukarıdaki iki soruya verdiğim cevaptan;

a. Eminim.

b. Emin değilim.

4.1. Sera etkisi bizim için yararlı mı yoksa zararlı mıdır?
a. Yararlidir.
b. Zararlidir.
c. a ve b
d. Etkisizdir.

4.2. Yukarıda verdiğim cevabın sebebi;

a. Sera etkisinin insanoğluna ne zararı nede yararı vardır.

b. Sera etkisi doğal bir olaydır, normalden fazla olması zararlıdır.

c. Sera etkisi kış aylarında da sebze yiyebildiğimiz için yararlıdır.

d. Sera etkisi ozon tabakasını deldiği için zararlıdır.

4.3. Yukarıdaki iki soruya verdiğim cevaptan;
a. Eminim.
b. Emin değilim.

5.1. Aşağıdakilerden hangisi küresel ısınmayı durdurmak için etkili değildir?
a. Daha çok kağıt geri dönüşümü yapmak.
b. Kurşunsuz benzin kullanmak.
c. Yenilenebilir enerji kaynaklarından elektrik elde etmek.
d. Kloroflorokarbon (CFC) içeren deodorant vb. spreyleri daha az kullanmak.

5.2. Yukarıda verdiğim cevabın sebebi;

a. Sprey kutularında bulunan kloroflorokarbonlar (CFC) ozon tabakasını deler.

b. Yenilenebilir enerji kaynakları kullanmak enerjinin korunması demektir.

c. Geri dönüşüm yapmak sadece ormanlarımızın kesilmesi ile alakalıdır.

d. Kursunun canlı organizmalar üzerinde zehirli etkisi vardır.

e.

5.3. Yukarıdaki iki soruya verdiğim cevaptan;
a. Eminim
b. Emin değilim.

6.1. Küresel ısınmayı durdurmak için yöneticiler neler yapmalıdırlar?
a. Fabrikaların nehirlere attığı kimyasal atıklara sınırlama getirilmelidirler.
b. Nükleer enerji santralleri kurmamalıdırlar.
c. Tarımsal faaliyetlerde böcek ilacı kullanımına sınırlama getirmelidirler.
d. Ağaçlandırma kampanyaları yürütmelidirler.

6.2. Yukarıda verdiğim cevabın sebebi;

a. Nükleer enerji kullanımı çevre dostu olmayan bir davranıştır.

b. Bir ağaç ömrü boyunca 1 ton karbondioksit $\left(\mathrm{CO}_{2}\right)$ emmektedir. 
c. Böcek ilacı kullanımı sınırlandırılarak küresel ısınma azaltılabilir.

d. Nehirlerin kirlenmesi ekosisteme zarar vererek küresel 1sınmaya neden olur.

6.3. Yukarıdaki iki soruya verdiğim cevaptan;

a. Eminim.

b. Emin değilim.

7.1 Ozon tabakas1,

a. Dünyayı asit yağmurlarından korur.

b. Güneşten gelen ultraviyole (UV) ışınlarını filtreler.

c. Dünyanın ısısını sabit tutarak onu yaşanılır yapar.

7.2 Yukarıda verdiğim cevabın sebebi;

a. Ozon tabakası güneşin hayatı olumsuz etkileyebilen ultraviyole (UV) 1şınlarını soğurur.

b. Ozon tabakası güneş ışınlarının atmosferin dışına çıkmasını engelleyerek dünya 1sısını yaşanılır kılar.

c. Ozon tabakası bir kalkan gibi çalışarak asit yağmurlarının dünya yüzeyine ulaşmasını engeller.

7.3 Yukarıdaki iki soruya verdiğim cevaptan;
a. Eminim.
b. Emin değilim.

8.1. Aşağıdakilerden hangisi ozon tabakasındaki incelmenin nedenlerinden birisidir?
a. Karbondioksit $\left(\mathrm{CO}_{2}\right)$
b. Sera Etkisi
c. Nükleer Enerji Santralleri
d. Karbon monoksit (CO)
e. Kloroflorokarbon (CFC) içeren ürünler

8.2. Yukarıda verdiğim cevabın sebebi;

a. Nükleer santrallerden gelen radyoaktif atıklar ozon ile reaksiyon verebilir.

b. Karbondioksitin $\left(\mathrm{CO}_{2}\right)$ dünyamızı kirletici ve yıkıcı bir etkisi vardır.

c. Kloroflorokarbon (CFC) içeren aerosoller ozon tabasının incelmesine neden olur.

d. Sera etkisi küresel ısınmayı arttırarak ozon tabakasına zarar verir.

e. Ozon tabakasının incelmesine fabrika bacalarından çıkan karbon monoksit neden olur

f.

8.3. Yukarıdaki iki soruya verdiğim cevaptan;
a. Eminim.
b. Emin değilim.

9.1. Aşağıdakilerden hangisi ozon tabakasındaki incelmenin sonuçlarından birisidir?
a. Su baskınlarında artış
b. Atmosfere daha fazla güneş ışınının ulaşması
c. Atmosferden uzaya hava kaçması
d. Cilt kanseri ve katarakt vakalarında artış
e. Küresel 1sınmanın artması

9.2. Yukarıda verdiğim cevabın sebebi;

a. Ozon tabakasının incelmesi ile kutuplardaki buzullar eriyecektir.

b. Artan ultraviyole (UV) ışınlarının insan sağlığ üzerinde olumsuz etkileri vardır. 
c. İncelen ozon tabakası, dünyaya güneşin radyasyonunun girişini engelleyememektir

d. Denizlerde buharlaşma artacağından deniz canlılarının nesli tehlikeye girecektir

e. Ozon tabakasında açılan delik, havanın uzaya kaçmasına zemin hazırlar.

f. Ozon tabakasındaki incelme ile daha fazla güneş ışını atmosfere girecektir

g.

9.3. Yukarıdaki iki soruya verdiğim cevaptan;
a. Eminim.
b. Emin değilim.

10.1. Ozon tabakasındaki incelmeyi durdurmak için neler yapabiliriz?
a. Toplu taşıma araçlarını kullanmalıyız.
b. Fabrika bacalarına ve egzozlara filtre takmalıyı.
c. Kloroflorokarbonlu (CFC) deodorant vb. spreyleri kullanmamalıyız.

10.2. Yukarıda verdiğim cevabın sebebi;

a. Fabrikaların kimyasal atıkları ozon tabakasının incelmesine neden olur.

b. Karbondioksit $\left(\mathrm{CO}_{2}\right)$ oluşumunu azaltmak ozon tabakasının incelmesini azaltır.

c. Kloroflorokarbonlu(CFC) ürünlerin kullanımını azaltmak ozon tabakasının incelmesini azaltır.

d.

10.3. Yukarıdaki iki soruya verdiğim cevaptan;
a. Eminim.
b. Emin değilim.

11.1. Aşağıdakiler cümlelerden hangisi asit yağmurları için doğru bir ifadedir?

a. Metanın $\left(\mathrm{CH}_{4}\right)$ atmosferde birikmesi ile asit yağmurları oluşur.

b. Fosil yakıtların yanması ile oluşan atıkların su döngüsüne karışması sonucu oluşur.

c. Ozon tabakasının incelmesi asit yağmurlarının oluşmasına neden olur.

11.2 Yukarıda verdiğim cevabın sebebi;

a. Kloroflorokarbonlar (CFC) asit yağmurlarının oluşmasında katkıda bulunmasıdır.

b. Atık toplama alanlarından oluşan zararlı gazlar asit yağmurlarına neden olmasıdır.

c. Doğal asitlerin yağmurla toprağa inmesi sonucunda oluşmasıdır

d. Asit yağmurlarının yanan fosil yakıtların sebep olduğu hava kirliliği sonucunda oluşmasıdır. e.

11.3. Yukarıdaki iki soruya verdiğim cevaptan;
a. Eminim.
b. Emin değilim.

12.1. Aşağıdakilerden hangisi asit yağmurlarının sonuçlarından biridir?
a. Ozon tabakasinin incelmesi
b. Küresel isınmanın artması.
c. Binalara, büstlere ve tarihi yapılara zarar vermesi.
d. Bazı bitki ve hayvanların hayatta kalmasına destek olması.
e. Temas ettiği her şeyi yakması.

12.2. Yukarıda verdiğim cevabın sebebi;

a. Asit yağmurları asidik olduğu için temas ettiği her şeyi yakmasıdır.

b. Bazı bitki ve hayvanların normal yağışlara olduğu gibi asit yağmurlarına ihtiyacı olmasıdır. 
c. Asit yağmurları daha fazla güneş ışınını soğurduğu için küresel ısınmayı artırmasıdır.

d. Asit yağmurlarındaki sülfürik asit $\left(\mathrm{H}_{2} \mathrm{SO}_{4}\right)$ stratosferdeki ozon tabakasını inceltmesidir.

e. Yapılardaki mermer ve kireçtaşı gibi malzemelerin aşınmasına katkıda bulunmasıdır.

f.......

12.3. Yukarıdaki iki soruya verdiğim cevaptan;

a. Eminim.

b. Emin değilim.

13.1. Aşağıdakilerden hangisi asit yağmurlarını karşı alabileceğimiz önlemlerden biridir?

a. Ozon tabakasına zarar veren davranışlardan kaçınmalıyız.

b. Enerji kaynağı olarak fosil yakıt kullanımını azaltmalıyız

c. Karbon monoksit (CO) emisyonlarına limit koymalıyız.

13.2. Yukarıda verdiğim cevabın sebebi;

a. Karbon monoksitin (CO) asit yağmurlarının başlıca nedeni olmasıdır.

b. Ozon tabakasının dünyayı asit yağmurlarından korumasıdır.

c. Fosil yakıt kullanımı sonucu oluşan atıkların asit yağmuru oluşturmasıdır.

d.

13.3. Yukarıdaki iki soruya verdiğim cevaptan;

a. Eminim.

b. Emin değilim. 